\title{
Outward Currents through the Inwardly Rectifying Potassium Channel of Guinea-Pig Ventricular Cells
}

\author{
Akihiro SAIGUSA* and Hiroko MatSUdA** \\ * National Institute for Physiological Sciences, \\ Okazaki, 444 Japan \\ ** Department of Physiology, School of Medicine, \\ Kyushu University, Fukuoka, 812 Japan
}

\begin{abstract}
Currents through the inwardly, rectifying $\mathrm{K}$ channel were studied under whole-cell clamp of collagenase-treated single ventricular cells of guinea-pigs. The inwardly rectifying $\mathrm{K}$ channel was fully activated by hyperpolarizing the membrane from the equilibrium potential for $\mathrm{K}^{+}$ $\left(E_{\mathrm{K}}\right)$ by $30-40 \mathrm{mV}$. Following depolarization above $E_{\mathrm{K}}$, a decaying outward current was elicited. Prolongation of the hyperpolarizing prepulse increased the amplitude of the decaying outward current, with a time course similar to the increase of the inward current during the prepulse. Time-dependent changes in both outward and inward currents could be fitted with a single exponential function and were attributed to deactivation and activation of the inwardly rectifying $\mathrm{K}$ channel. The instantaneous current-voltage relation was almost linear, indicating that the conductance of the channel is ohmic and that the rectification of the steady-state current was due to the kinetic properties of the inwardly rectifying $\mathrm{K}$ channel. The activation kinetics of the channel was measured at different concentrations of $\mathrm{K}^{+}$in both the external and internal solutions. The time constant and the steady-state activation were not a function of the absolute membrane potential value, but were dependent on the driving force.
\end{abstract}

Key words: inwardly rectifying $\mathrm{K}$ channel, internal perfusion, single ventricular cell, whole cell clamp.

In the heart cells, the inwardly rectifying $\mathrm{K}$ channel is the major source of the $\mathrm{K}$ conductance to hold the resting membrane potential close to the equilibrium potential for $\mathrm{K}^{+}\left(E_{\mathrm{K}}\right)$. The conductance associated with this channel is markedly

Received for publication December 4, 1987

* Present address: 2nd Department of Internal Medicine, Jikei University School of Medicine, Tokyo, 105 Japan

** Present address: Department of Physiology, University of Leicester, University Road, Leicester LE1 7RH, U.K. 
reduced at the potential range of the plateau of the action potential, which allows the action potential duration to last for several hundred milliseconds. In spite of its physiologically important functions, studies of the outward current component of the inwardly rectifying $\mathrm{K}$ channel are few (Hagiwara et al., 1976; Hestrin, 1981; LEECH and STANFIELD, 1981), simply because of the difficulty of observing the outward current.

We reported previously that a decaying outward current through the inwardly rectifying $\mathrm{K}$ channel was elicited on stepping the membrane potential to values more positive than $E_{\mathrm{K}}$, which was shifted in the positive direction by perfusing the cells with Cs-rich internal solution, and that its decay was accelerated with larger depolarization (MATSUDA and NOMA, 1984). To exclude the effect, if any, of internal $\mathrm{Cs}^{+}$on the channel in these experiments (OHMORI, 1984), in this work we changed $E_{\mathrm{K}}$ by increasing the external $\mathrm{K}^{+}$concentration $\left(\left[\mathrm{K}^{+}\right]_{\mathrm{o}}\right)$ or decreasing the internal $\mathrm{K}^{+}$concentration $\left(\left[\mathrm{K}^{+}\right]_{\mathrm{i}}\right)$ using substitutes other than $\mathrm{Cs}^{+}$and so extended the findings on the outward currents through the inwardly rectifying $\mathrm{K}$ channel. The results suggest that unitary conductance of the inwardly rectifying $\mathrm{K}$ channel isohmic and that gating kinetics depends on $\left[\mathrm{K}^{+}\right]_{i}$ as well as on $\left[\mathrm{K}^{+}\right]_{0}$. This finding is different from results of the previous studies in different tissues that the gating kinetics of the inward rectifier depends on $\left[\mathrm{K}^{+}\right]_{0}$, but not on $\left[\mathrm{K}^{+}\right]_{i}$ (HaGIWARA and Yoshit, 1979; Hestrin, 1981; LeECh and Stanfield, 1981). Parts of this work have appeared elsewhere (MATSUDA et al., 1987).

\section{MATERIALS AND METHODS}

Preparations of isolated single ventricular cells. Guinea-pigs of $300-600 \mathrm{~g}$ were anesthetized with pentobarbital sodium $(40-60 \mathrm{mg} / \mathrm{kg})$. Under artificial respiration, we opened the chest and cannulated the aorta in situ to perfuse the coronary artery with a hydrostatic pressure of approximately $65 \mathrm{cmH}_{2} \mathrm{O}$, and isolated the heart. The blood was washed out by coronary perfusion with Tyrode's solution equilibrated with a $100 \%-\mathrm{O}_{2}$ gas. The composition of the Tyrode's solution was (in $\mathrm{mm}$ ): $\mathrm{NaCl}, 143.9 ; \mathrm{KCl}, 5.4 ; \mathrm{CaCl}_{2}, 1.8 ; \mathrm{MgCl}_{2}, 0.5$; glucose, 5.5; $\mathrm{NaH}_{2} \mathrm{PO}_{4}$, 0.33 ; and $5 \mathrm{~mm}$ HEPES-NaOH buffer $(\mathrm{pH}=7.4)$. After the heart was perfused with about $100 \mathrm{ml}$ of Ca-free Tyrode's solution, the solution was switched to a Ca-free Tyrode's solution containing $0.04 \mathrm{mg} / \mathrm{ml}$ collagenase (Sigma type I), which was recirculated with a peristaltic pump for $40 \mathrm{~min}$. Thereafter, $100 \mathrm{ml}$ of a high-K storage solution (see below; ISENBERG and KLÖCKNER, 1982) was perfused to wash out collagenase. The composition of the high-K storage solution was (in $\mathrm{mm}$ ): taurine, 10; glutamic acid, 70; $\mathrm{KCl}, 25 ; \mathrm{KH}_{2} \mathrm{PO}_{4}, 10 ; \mathrm{MgCl}_{2}, 3$; glucose, 11; ethyleneglycol-bis $\left(\beta\right.$-aminoethylether) $\mathrm{N}, \mathrm{N}^{\prime}$-tetraacetic acid (EGTA), 0.5; and HEPES, 10 ; and $\mathrm{pH}$ adjusted to 7.4 with $\mathrm{KOH}$. After washing out collagenase, the ventricles were chopped in the high-K storage solution and the cell suspension was filtered with a $100 \mu \mathrm{m}$ stainless steel mesh net to separate single cells. The isolated cells were stored in the high-K solution at $4 \mathrm{C}$ for the later use. The temperature of 
all perfusates was kept at $36-37{ }^{\circ} \mathrm{C}$ during coronary perfusion.

Electrodes. Patch electrodes were fabricated from capillaries of high melting temperature glass and the inner tip diameter was $3-5 \mu \mathrm{m}$. The electrode tip was heat-polished and was filled with the internal solution. The electrode resistance ranged between 1 and $3 \mathrm{M} \Omega$.

Solutions. The compositions of the test solutions are listed in Table 1. Initially, we filled the electrode with the internal solution containing $1 \mathrm{mM} \mathrm{CaCl}_{2}$ instead of $5 \mathrm{~mm}$ EGTA, a procedure which makes the "G $\Omega$ seal" easier to obtain. After the "G $\Omega$ seal" was established, the internal solution was changed to a given one containing EGTA and then the cell membrane at the tip of the electrode was ruptured. The method for exchanging the solution in the patch electrode was the same as described elsewhere (SoEJima and NomA, 1984). To remove current flow through channels other than the $\mathrm{K}$ channel, external $\mathrm{Na}^{+}$was replaced with $\mathrm{Tris}^{+}$. and $\mathrm{Cd}^{2+}$ was added to the external solution. In the standard experiment $40 \mathrm{~mm}$ $\mathrm{K}^{+}$external solution and $150 \mathrm{mM} \mathrm{K}^{+}$internal solution were used. The temperature of solutions in the chamber was kept at $14-15^{\circ} \mathrm{C}$ to slow the kinetics and to facilitate analysis.

Recording techniques. The single-pipette whole-cell clamp technique is similar to those described by Hamill et al. 1981. Compensation of the series resistance at the tip of the patch electrode was described previously (OHARA et al.. 1983). When

Table 1. Composition of solutions (in $\mathrm{mM}$ ).

\begin{tabular}{|c|c|c|c|c|c|c|c|c|c|}
\hline & \multicolumn{9}{|c|}{ External solution } \\
\hline & Tris $\mathrm{Cl}$ & $\mathrm{KCl}$ & $\mathrm{MgCl}_{2}$ & $\mathrm{Ca}$ & $\mathrm{Cl}_{2}$ & $\mathrm{Cd}$ & $\mathrm{Cl}_{2}$ & Glucose & $V_{\mathrm{j}}(\mathrm{mV})$ \\
\hline $40 \mathrm{~K}^{+}$solution & 114 & 40 & 0.5 & & 8 & 0 . & 1 & 5.5 & +2 \\
\hline $20 \mathrm{~K}^{+}$solution & 134 & 20 & 0.5 & & 8 & 0. & 1 & 5.5 & +3 \\
\hline $80 \mathrm{~K}^{+}$solution & 74 & 80 & 0.5 & & 8 & 0 . & 1 & 5.5 & 0 \\
\hline \multirow[t]{3}{*}{$0 \mathrm{~K}^{+}$solution } & 154 & 0 & 0.5 & & 8 & 0 . & 1 & 5.5 & +4 \\
\hline & \multicolumn{9}{|c|}{ Internal solution } \\
\hline & $\mathrm{K}$-aspartate & $\mathrm{KCl}$ & EGTA & $\mathrm{K}_{2}$-ATP & $\mathrm{HEI}$ & ES & $\mathrm{MgCl}_{2}{ }^{*}$ & * Glucose & $V_{\mathrm{j}}(\mathrm{mV})$ \\
\hline $150 \mathrm{~K}^{+}$solution & 120 & 20 & 5 & 5 & 5 & 5 & 1 & 0 & -13 \\
\hline $75 \mathrm{~K}^{+}$solution & 45 & 20 & 5 & 5 & 5 & 5 & 1 & 150 & -10 \\
\hline $50 \mathrm{~K}^{+}$solution & 20 & 20 & 5 & 5 & 5 & 5 & 1 & 200 & -9.5 \\
\hline
\end{tabular}

The $\mathrm{pH}$ of external solutions was adjusted to 7.4 (with Tris buffer) and the $\mathrm{pH}$ of the internal solutions was adjusted to 7.3 with $5 \mathrm{~mm}$ HEPES-KOH. $V_{\mathrm{j}}$ was the liquid junction potential between the solution and the Tyrode solution. The sign was positive when the side of Tyrode solution was negative. Correction of the membrane potentials was made as described by HaGiWARA and OHMORI (1982). ${ }^{*}$ Free $\mathrm{Mg}^{2+}$ concentration calcutated from the apparent dissociation constants (FABIATO and FABIATO, 1979) is $15 \mu \mathrm{M}$. 
the tip of the electrode was in the Tyrode's solution, the command D.C. potential was adjusted to make the current through the electrode zero, and this voltage was taken as the reference potential. The resistance of the electrode was measured from the amplitude of the current produced by $1 \mathrm{mV}$ voltage pulse. After the electrode tip was attached to the cell surface, a negative pressure of $30-70 \mathrm{~cm} \mathrm{H}_{2} \mathrm{O}$ was applied to interior of the electrode, and the "G $\Omega$ seal" was usually established within 1 to $2 \mathrm{~min}$. After changing the internal solution containing $1 \mathrm{mM} \mathrm{CaCl}_{2}$, to the other containing $5 \mathrm{~mm}$ EGTA, the membrane at the tip of the electrode was ruptured by applying further brief suction, and the repture was detected by a sudden increase of the capacitive current. The membrane potentiel was held and around the zerocurrent potential and voltage steps were applied every $6 \mathrm{~s}$, unless otherwise indicated. Current and voltage were recorded on the magnetic tape (TEAC, R-210), and they were analyzed using a computer (NEC, PC-98XA).

\section{RESULTS}

The inwardly rectifying $K$ channel current

Figure 1 shows a typical experiment to observe outward current through the inwardly rectifying $\mathrm{K}$ channel. The uppermost trace of the left column represents the voltage step and traces in $\mathrm{A}$ and $\mathrm{B}$ represent the current records in response to it, with $150 \mathrm{~mm} \mathrm{~K}^{+}$internal solution at $40 \mathrm{~mm}\left[\mathrm{~K}^{+}\right]_{\mathrm{o}}$ and $0 \mathrm{~mm}\left[\mathrm{~K}^{+}\right]_{0}$, respectively. The membrane potential was held at $-30 \mathrm{mV}$, which is close to $E_{\mathrm{K}}$ predicted from the transmembrane $\mathrm{K}^{+}$concentrations $\left(150 \mathrm{~mm}\left[\mathrm{~K}^{+}\right]_{i}\right.$; and $\left.40 \mathrm{mM}\left[\mathrm{K}^{+}\right]_{0}\right),-32 \mathrm{mV}$. In the presence of $40 \mathrm{~mm}\left[\mathrm{~K}^{+}\right]_{0}$, the inwardly rectifying $\mathrm{K}$ channel was activated by a hyperpolarizing prepulse of $40 \mathrm{mV}$. A subsequent test pulse to a value $15 \mathrm{mV}$ positive to the zero-current potential elicited a decaying outward current (Fig. 1A). Since external $\mathrm{Na}^{+}$was replaced with $\mathrm{Tris}^{+}$and $\mathrm{Ca}$ current was blocked by $\mathrm{Cd}^{2+}$, neither $\mathrm{Na}$ nor $\mathrm{Ca}$ channels are responsible for this outward current. The decay of the outward current can be fitted with a single exponential function (Fig. 1D), with a time constant $(\tau)$ of $4.09 \mathrm{~ms}$. At $0 \mathrm{~mm}\left[\mathrm{~K}^{+}\right]_{0}$, both the inward and outward current disappeared, leaving capacitive currents proportional to the value of voltage step (Fig. 1B), suggesting that the decaying outward current flows through the inwardly rectifying $\mathrm{K}$ channel. Figure $\mathrm{IC}$ shows the difference current obtained by subtracting the current in Fig. 1B from the one in Fig. 1A. The time constant of the decay measured from this difference current was identical to that obtained from the original record in Fig. 1A (Fig. 1E), suggesting that the separation of the ionic current from the capacitive current is satisfactory.

To show that the decaying current flows through the inwardly rectifying $\mathrm{K}$ channel, the outward current was elicited after the inwardly rectifying $K$ channel was activated to different degrees by varying the duration of the preceding hyperpolarizing pulse (Fig. 2). The amplitude of the outward current increased in parallel with the activation of the inward current and reached a steady level $20 \mathrm{~ms}$ after the onset of the hyperpolarizing pulse when the inward current attained a 


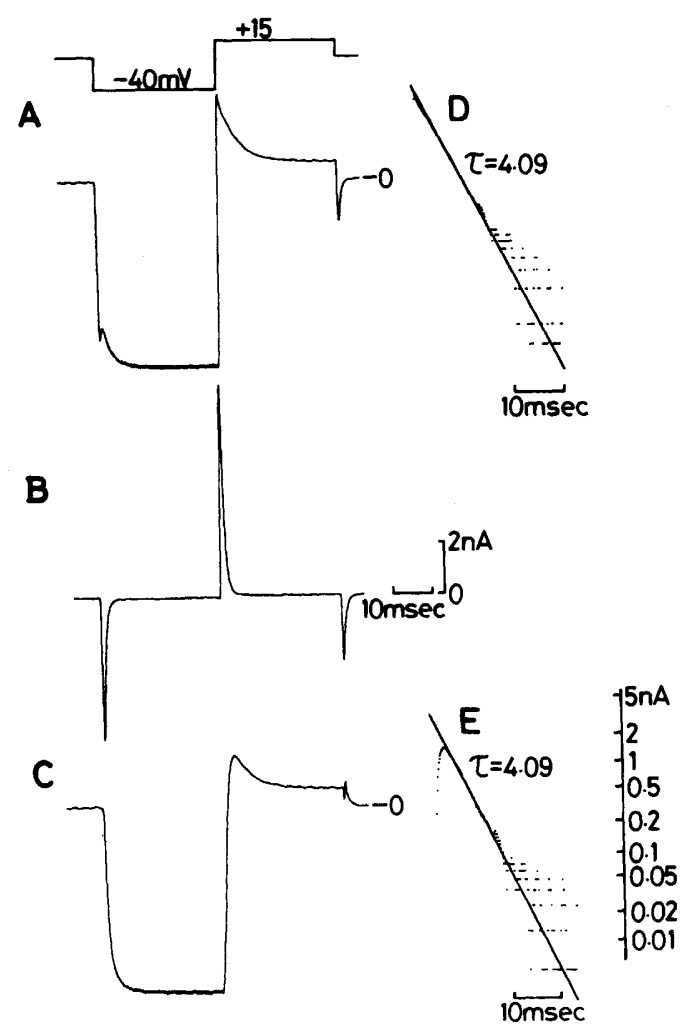

Fig. 1. Outward current through the inwardly rectifying $\mathrm{K}$ channel. The uppermost trace in the left column shows the voltage step. The figure indicates a voltage deviation from the holding potential set at around the zero-current potential. A and B: the current traces obtained at $40 \mathrm{~mm}\left[\mathrm{~K}^{+}\right]_{o}$ and $0 \mathrm{~mm}\left[\mathrm{~K}^{+}\right]_{o} ;\left[\mathrm{K}^{+}\right]_{i}, 150 \mathrm{~mm}$. C: the difference current obtained by subtracting the current in $\mathrm{B}$ from that in $\mathrm{A}$. D and $\mathrm{E}$ : the difference between the actual current and its steady-state value during depolarization plotted against time on a semi-logarithmic plot. The decay of the outward current can be fitted with a single exponential function having a time constant $(\tau)$ of $4.09 \mathrm{~ms}$ both before (D) and after (E) subtraction of the capacitive currents.

plateau level. The time course of the development of the outward current was fitted with a single exponential function having a time constant of $4.6 \mathrm{~ms}$ (Fig. 2B), which agreed well with the time constant of $4.4 \mathrm{~ms}$ in the current activation during the prepulse (Fig. 2C). This result supports the view that the outward current flows through the inwardly rectifying $K$ channel, which was activated during the preceding hyperpolarization.

A possible alternative explanation for this decaying outward current is the contribution of the transient outward current, which is widely observed in other tissues (for review see CARMELIET and VerEECKE, 1979). The transient outward 

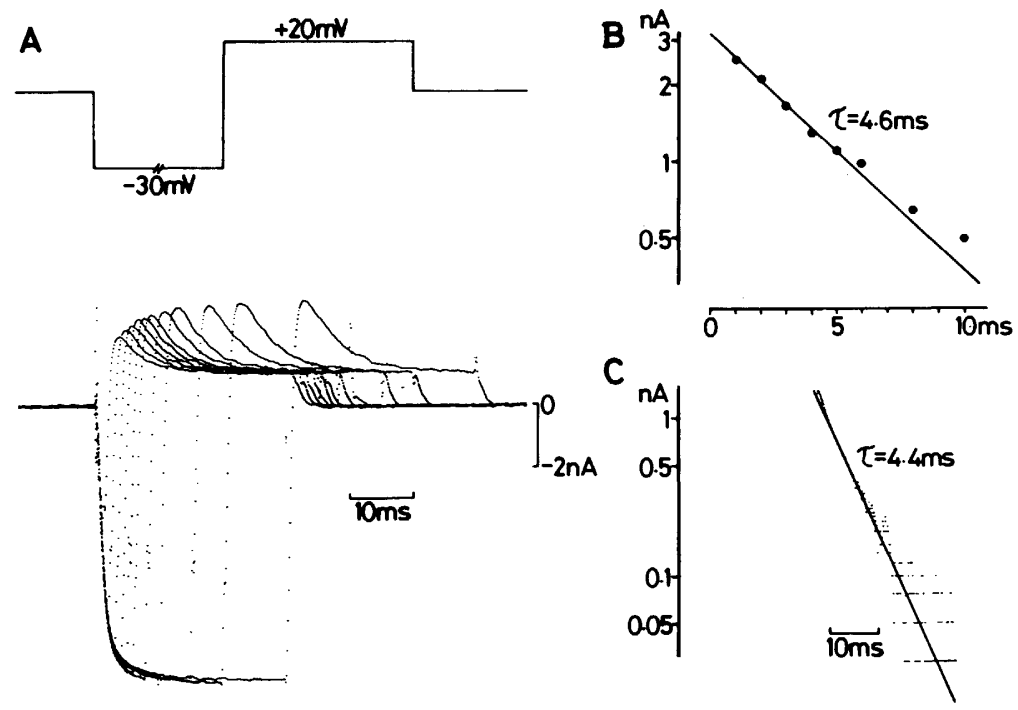

Fig. 2. Correlation between the time-dependent increase of the inward current during hyperpolarization and the decaying outward current during depolarization. A: the upper panel indicates the potential protocol where the hyperpolarizing prepulse was prolonged progressively, and the lower panel indicates the superimposed current traces. They correspond, from left to right, to hyperpolarizing pulses of duration 1 , $2,3,4,5,6,8,10,15,20$, and $30 \mathrm{~ms}$, respectively. The capacitive currents were subtracted. The figure in the pulse protocol indicates a voltage deviation from the holding potential. $\left[\mathrm{K}^{+}\right]_{\mathrm{o}}, 40 \mathrm{~mm} ;\left[\mathrm{K}^{+}\right]_{\mathrm{i}}, 150 \mathrm{~mm}$. B: the instantaneous outward current was obtained by extrapolating the best fitted curve to the onset of the depolarizing pulse and subtracted from its maximum value. The resulting value was plotted against the duration of the preceding pulse on a semi-logarithmic plot. A line giving a time constant of $4.6 \mathrm{~ms}$ was fitted by eye. C: the semi-logarithmic plot of the inward current during the $30 \mathrm{~ms}$ hyperpolarizing pulse. The increase of the inward current can be fitted with a single exponential function having a time constant of $4.4 \mathrm{~ms}$.

current, however, is observed much less frequently in quinea-pig ventricular cells than in rat ventricular cells. It is inactivated at around $-40 \mathrm{mV}$ and recovers slowly. The revovery time constant from inactivation of the transient outward current measured in rabbit atrioventricular node cells was $3.58 \mathrm{~s}$ at the holding potential of $-70 \mathrm{mV}$ (NAKAYAMA and IRISAWA, 1985). To exclude the possibility of the contribution of transient outward current, the recovery process of the outward current under investigation was examined (Fig. 3). A pair of depolarizing pulses to $+6 \mathrm{mV}$ was applied from the holding potential of $-99 \mathrm{mV}$ with various interpulse intervals. The current elicited with an interval of $30 \mathrm{~ms}$ showed an amplitude almost equal to that elicited by the first pulse. The decay of the transient outward current was fitted with two exponential components (NaKaYAma and IRISAWA, 1985). The 


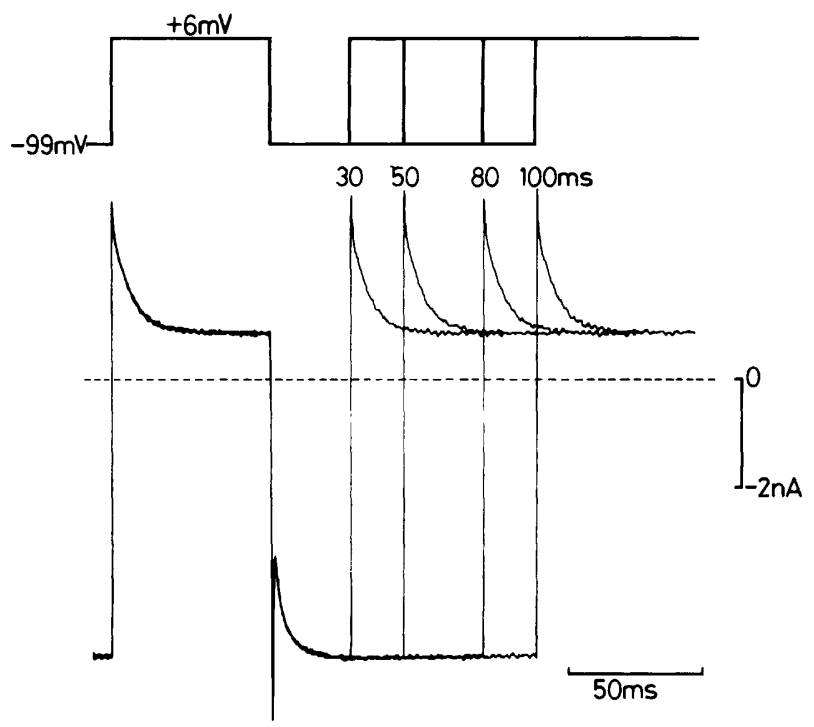

Fig. 3. Fast recovery of the outward current. The pulse protocol is shown in the upper panel and the current records are superimposed in the lower panel. Note that the decaying outward current apparently recovered during hyperpolarization of $30 \mathrm{~ms}$. The figures indicate the membrane potentials and the interval between a pair of depolarizing pulses. $\left[\mathrm{K}^{+}\right]_{0}, 40 \mathrm{~mm} ;\left[\mathrm{K}^{+}\right]_{\mathrm{i}}, 150 \mathrm{~mm}$.

time constant of the fast component was much slower than that of the outward current shown in the present study, which gives another argument against the contribution of the transient outward current.

Properties of outward current through inwardly rectifying $K$ channels at different external $K^{+}$concentrations

The results presented so far strongly suggest that the outward current under investigation flows through the inwardly rectifying $\mathrm{K}$ channel. Based on these results, we measured the instantaneous current-voltage relation and activation kinetics to know the mechanism of the inward rectification. We also studied the effects of the external and internal $\mathrm{K}^{+}$on the conductance and activation kinetics.

a) Current-voltage relationship. Outward current was elicited by depolarizing the membrane to various voltages after activating the inwardly rectifying $\mathrm{K}$ channel with a hyperpolarizing pulse. The amplitude of the instantaneous current was measured after subtraction of the capacitive currents by extrapolating the best fitted curve to the onset of the test pulse (Fig. 1E). Figure 4 shows the instantaneous and steady-state current-voltage curves at $\left[\mathrm{K}^{+}\right]_{0}$ of 0,40 , and $80 \mathrm{~mm}$, and a fixed $\left[\mathrm{K}^{+}\right]_{\mathrm{i}}$ of $150 \mathrm{~mm}$. By changing $\left[\mathrm{K}^{+}\right]_{\mathrm{o}}$ from 40 to $20 \mathrm{~mm}$ (not shown in Fig. 4) and to $80 \mathrm{~mm}$, the zero-current potential changed an average from $-26.0 \pm 2.0(n=6)$ to $-42.3 \pm 2.5 \mathrm{mV}(n=6)$ and to $-10.0 \pm 2.6 \mathrm{mV}(n=6)$, respectively. Such behavior 


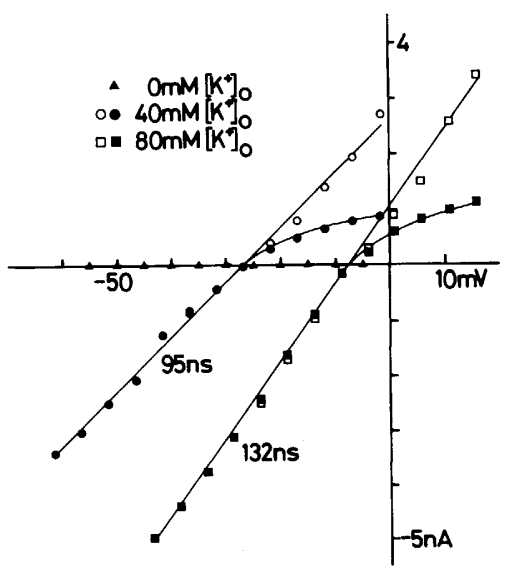

Fig. 4. The instantaneous (open symbols) and steady-state (filled symbols) currentvoltage curves at 0,40 , and $80 \mathrm{~mm}$ external $\mathrm{K}^{+}$concentrations. The amplitude of instantaneous currents was measured by extrapolating the best fitted curve to the onset of the test pulse, after subtraction of the capacitive currents. The steady level was measured near the end of the test pulse of $30 \mathrm{~ms}$. The slope fitted to the instantaneous current by eye gives $95 \mathrm{nS}\left(40 \mathrm{~mm}\left[\mathrm{~K}^{+}\right]_{\mathrm{o}}\right)$ and $132 \mathrm{nS}\left(80 \mathrm{~mm}\left[\mathrm{~K}^{+}\right]_{0}\right)$. $\left[\mathrm{K}^{+}\right]_{\mathrm{i}}, 150 \mathrm{mM}$.

of the zero-current potential as a $\mathrm{K}$ electrode shows that it can be considered equal to $E_{\mathrm{K}}$. While the steady state current-voltage curve showed inward rectification at the voltages positive to $E_{\mathrm{K}}$, almost linear instantaneous current-voltage curves were obtained in 15 out of 21 cells in the standard experiments. This finding suggests that the current-voltage relation of the inwardly rectifying $\mathrm{K}$ channel is linear and that the rectification of the steady-state current is due to time-dependent closure of the channel on depolarization.

The slope conductance was increased by $1.32 \pm 0.09$ times $(n=5)$ when $\left[\mathrm{K}^{+}\right]_{\mathrm{o}}$ was doubled. This result agrees well to the previous studies that the conductance was roughly proportional to the square root of $\left[\mathrm{K}^{+}\right]_{\mathrm{o}}$ (HAGIWARA and TAKAHASHI, 1974).

b) Time constant $(\tau)$. The time constant of the inward or outward current change was examined at $\left[\mathrm{K}^{+}\right]_{\mathrm{o}}$ of 20,40 , and $80 \mathrm{~mm}$, and plotted against the voltage step $(\Delta V)$ from the zero-current potential (Fig. 5). The time constant decreased exponentially as the voltage step was increased ( $e$-fold decline for a $28.7 \mathrm{mv}$ hyperpolarization and for a $19.3 \mathrm{mV}$ depolarization) and the time constant-voltage relation was bell-shaped with the peak ( $8-9 \mathrm{~ms})$ at around $E_{\mathrm{K}}$. The relations between the average of time constant and voltage were almost superimposable $(n=6$, for each $\left[\mathrm{K}^{+}\right]_{0}$ ), in the range below $E_{\mathrm{K}}$ (HAGIWARA et al., 1976; LEECH and StANFIELD, 1981) and also above $E_{\mathrm{K}}$, if plotted the time constant against driving force.

c) The steady-state activation curve. The steady-state activation curve was measured by applying a test pulse of fixed amplitude following a prepulse of varying 


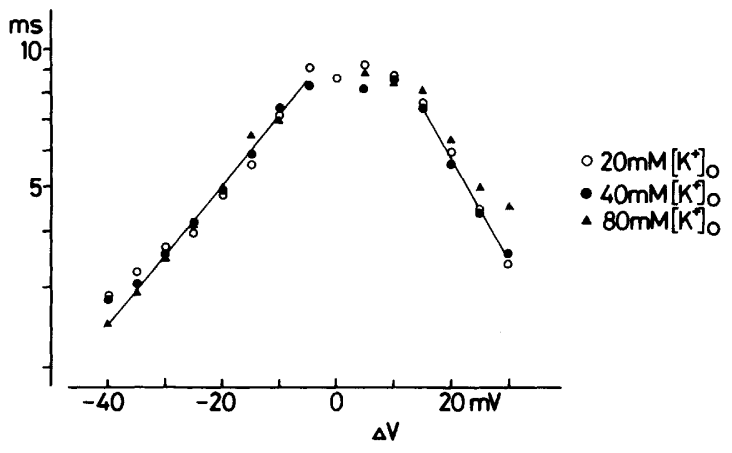

Fig. 5. The time constant-voltage relation at $\left[\mathrm{K}^{+}\right]_{\mathrm{o}}$ of 20,40 , and $80 \mathrm{~mm}$. The average of 6 experiments at each $\left[\mathrm{K}^{+}\right]_{0}$ is plotted against the voltage step $(\Delta V)$ from the zero-current potential. Open circles, $20 \mathrm{~mm}$; filled circles, $40 \mathrm{~mm}$; triangles, $80 \mathrm{~mm}$. $\left[\mathrm{K}^{+}\right]_{\mathrm{i}}, 150 \mathrm{~mm}$. The slope of the line fitted for the data at $40 \mathrm{~mm}\left[\mathrm{~K}^{+}\right]_{\mathrm{o}}$ was $e$-fold change $/ 28.7 \mathrm{mV}$ and $e$-fold $/ 19.3 \mathrm{mV}$ for the positive and negative slope, respectively.

A

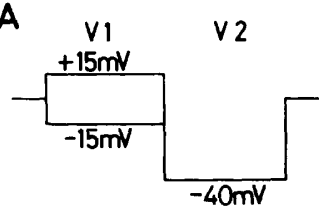

\section{B}

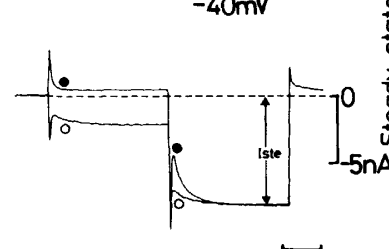

$10 \mathrm{~ms}$

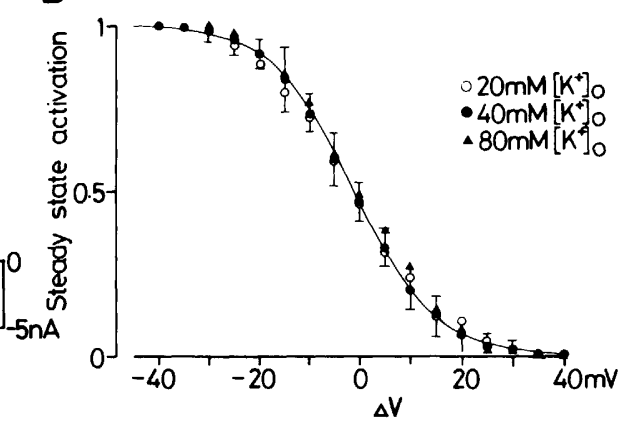

Fig. 6. The steady-state activation curve of the inwardly rectifying $\mathrm{K}$ channel. A: the amplitude of the first pulse $\left(V_{1}\right)$ was changed, while the second pulse $\left(V_{2}\right)$ was fixed to $\Delta V=-40 \mathrm{mV}$, where the channel was assumed to be fully activated. B: the average of 6 experiments of the steady-state activation at 20 (open circles), 40 (filled circles), and $80 \mathrm{~mm}$ (triangles). $\left[\mathrm{K}^{+}\right]_{\mathrm{o}}$ is plotted against $V_{1}$ expressed as $\Delta V$. The vertical bars indicate the standard deviation of the data obtained at $40 \mathrm{~mm}\left[\mathrm{~K}^{+}\right]_{0}$. The smooth curve is drawn using Eq. (2). $\left[\mathrm{K}^{+}\right]_{\mathrm{i}}, 150 \mathrm{~mm}$.

amplitude (Fig. 6). The difference between the instantaneous current and the steadystate current during the test pulse reflects the difference between the degree of steady-state activation at the prepulse voltage $\left(V_{1}\right)$ and that at the test pulse voltage $\left(V_{2}\right)$. The time-dependent increase in the inward current of hyperpolarization is larger with the prepulse of $\Delta V=+15 \mathrm{mV}$ (filled circle) than with the prepulse of $\Delta V=-15 \mathrm{mV}$ (open circle). It is evident that the inwardly rectifying $\mathrm{K}$ channel is deactivated more extensively during a conditioning pulse of $\Delta V=+15 \mathrm{mV}$ than of 
$\Delta V=-15 \mathrm{mV}$. The amplitude of the time-dependent change during $V_{2}(I)$ was obtained by extrapolating the best fitted curve to the onset of $V_{2}$. It reached a maximum value at $\Delta V \geqq+40 \mathrm{mV}$. The steady-state activation is assumed to be zero at $\Delta V \geqq+40 \mathrm{mV}$ (see Fig. 2 of MATSUdA et al., 1987) and complete at $\Delta V=-40 \mathrm{mV}$. The steady-state degree of activation, $y$, at potential $=\Delta V$ may then be defined as:

$$
y(\Delta V)=1-I / I_{\max }
$$

where $I_{\max }$ is the maximum amplitude of $I$.

In Fig. 6B, $y$ is plotted against $V_{1}$. The relations obtained at $\left[\mathrm{K}^{+}\right]_{0}$ of 20,40 , and $80 \mathrm{~mm}$ are all fitted with a common theoretical curve given by the following equation:

$$
y(\Delta V)=\left[1+\exp \left(\left(\Delta V-V_{\text {half }}\right) / v\right)\right]^{-1}
$$

where $r$ is the slope factor, and $V_{\text {hill }}$ indicates the voltage of half activation. As evident in Fig. $6 \mathrm{~B}$, the steady-state activation curve at different $[\mathrm{K}]_{0}$ was almost superimposable, if plotted against $\Delta V$. For simplicity, only the curve fitted to the data at $40 \mathrm{~mm}\left[\mathrm{~K}^{+}\right]_{0}$ is shown with the standard deviations. It has a slope factor of $7.98 \mathrm{mV}$ and a half activation voltage of $E_{\mathrm{K}}-1.2 \mathrm{mV}$.

\section{The effect of the internal $K$ concentration}

Previous studies showed that the gating kinetics and conductance of the inwardly rectifying $\mathrm{K}$ channel did not depend on driving force when $E_{\mathrm{K}}$ was altered by changing $\left[\mathrm{K}^{+}\right]_{\mathrm{i}}$ (Hagiwara and YoshiI, 1979; Hestrin, 1981; LeECH and STANFIELD, 1981). When $\left[\mathrm{K}^{+}\right]_{\mathrm{i}}$ was reduced from 150 to $75 \mathrm{~mm}$ and further to $50 \mathrm{~mm}$ in this study, however, different results were obtained. Figure 7 shows the currentvoltage curves determined with $150 \mathrm{~mm}\left[\mathrm{~K}^{+}\right]_{i}$ and $75 \mathrm{~mm}\left[\mathrm{~K}^{+}\right]_{i}$ at $40 \mathrm{~mm}\left[\mathrm{~K}^{+}\right]_{0}$. The instantaneous current-voltage curve was linear at each $\mathrm{K}^{+}$concentration. When $\left[\mathrm{K}^{+}\right]_{\mathrm{i}}$ was increased from 50 to $75 \mathrm{~mm}$, the slope conductance increased by $1.62 \pm 0.19$ times $(n=5)$. The zero-current potential was $-26.5 \pm 2.2(n=9)$, $-17.8 \pm 2.4(n=5)$, and $-11.1 \pm 2.2 \mathrm{mV}(n=4)$ with $\left[\mathrm{K}^{+}\right]_{\mathrm{i}}$ of 150,75 , and $50 \mathrm{~mm}$, respectively. The change of the zero-current potential is smaller than predicted from the Nernst equation $\left(17 \mathrm{mV}\right.$ by halving $\left[\mathrm{K}^{+}\right]_{\mathrm{i}}$; and $27 \mathrm{mV}$ as a result of reducing $\left[\mathrm{K}^{+}\right]_{\mathrm{i}}$ by two-thirds), suggesting that the efficiency of the internal perfusion was limited.

The time constants of the current change at a constant voltage in different $\left[\mathrm{K}^{+}\right]_{\mathrm{i}}$ were plotted against $\Delta V$ (Fig. 8), which were superimposable over the potential range negative to $E_{\mathrm{K}}$. At the voltage positive to $E_{\mathrm{K}}$ the deactivation time bacame slower in $75 \mathrm{~mm}\left[\mathrm{~K}^{+}\right]_{\mathrm{i}}$.

The steady-state activation-voltage relations measured using $\left[\mathrm{K}^{+}\right]_{\mathrm{i}}$ of 50,75 , and $150 \mathrm{~mm}$, are plotted against $\Delta V$ (Fig. 9). The curves with $150 \mathrm{~mm}\left[\mathrm{~K}^{+}\right]_{\mathrm{i}}$ and $75 \mathrm{~mm}\left[\mathrm{~K}^{+}\right]_{\mathrm{i}}$ were almost superimposable, and it shifted more positive direction with $50 \mathrm{~mm}\left[\mathrm{~K}^{+}\right]_{\mathrm{i}}$. We therefore concluded that the kinetics of the cardiac inwardly 


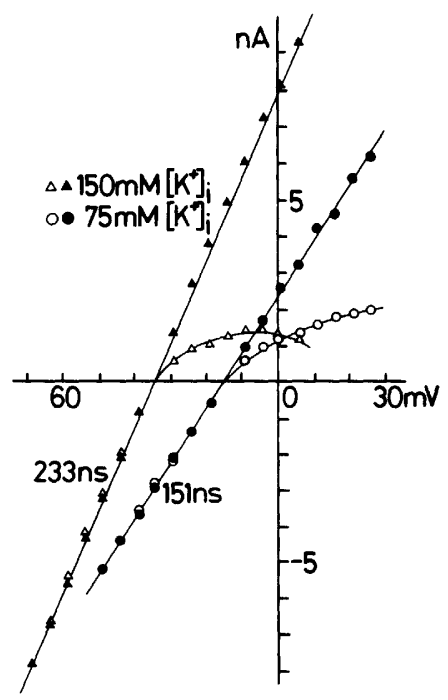

Fig. 7. Instantaneous (filled symbols) and steady state (open symbols) current-voltage curves determined with $150 \mathrm{mM} \mathrm{K}^{+}$(triangles) and $75 \mathrm{mM} \mathrm{K}^{+}$(circles) internal solutions. The slope conductance was $223 \mathrm{nS}$ with $150 \mathrm{~mm}\left[\mathrm{~K}^{+}\right]_{\mathrm{i}}$ and $151 \mathrm{nS}$ with $75 \mathrm{~mm}\left[\mathrm{~K}^{+}\right]_{\mathrm{i}} \cdot\left[\mathrm{K}^{+}\right]_{\mathrm{o}}, 40 \mathrm{~mm}$.

rectifying $\mathrm{K}$ channel is dependent on the driving force even when $E_{\mathrm{K}}$ is shifted by changing $\left[\mathrm{K}^{+}\right]_{\mathrm{i}}$.

\section{DISCUSSION}

In a previous paper (MATSUDA et al., 1987), we showed that the unitary conductance of the inwardly rectifying $\mathrm{K}$ channel is ohmic in the absence of intracellular $\mathrm{Mg}^{2+}$ and that the channel closes on depolarization because of voltage-dependent gating kinetics. We also found that internal $\mathrm{Mg}^{2+}$ blocks the outward current without affecting the inward current. We thus concluded that the inward rectification results from the gating kinetics of the inward rectifier $\mathrm{K}$ channel and the voltage-dependent block by internal $\mathrm{Mg}^{2+}$. Single channel recording enables precise analysis of the $\mathrm{Mg}$ block, but not investigation of the intrinsic gating kinetics, because the outward single channel currents, which can be seen only when the cell is opened to low Mg solution, become prolonged with time (MATSUDA, 1988). This prolongation is attributed to the washing out of a soluble gating component. In the whole-cell clamp experiments, where the washing out of the intracellular material should be much more limited than in the open cell-attached configuration of single channel recordings, the time constant of relaxation of the outward current was relatively stable during the experiment. Limited efficiency of the internal perfusion, however, made it difficult to lower internal $\mathrm{Mg}^{2+}$ enough to study the intrinsic gating kinetics (see below). Thus the activation kinetics of the 

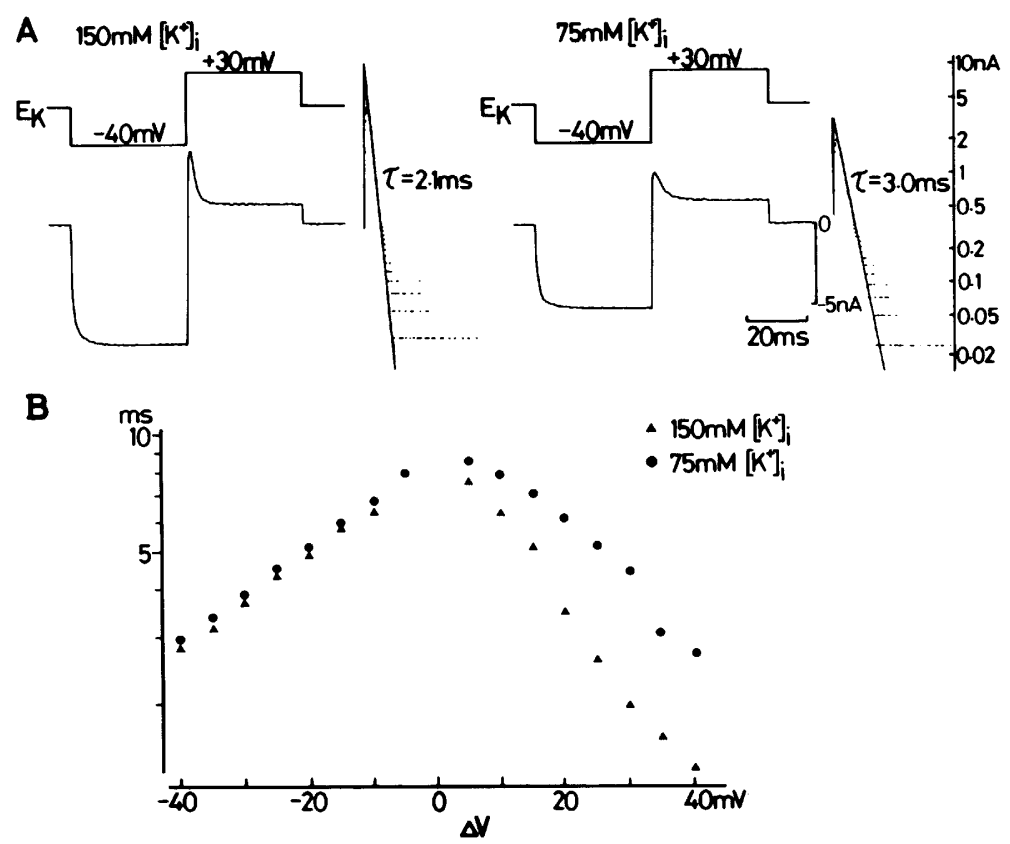

Fig. 8. A: current changes by reducing $\left[\mathrm{K}^{+}\right]_{\mathrm{i}}$ from 150 to $75 \mathrm{~mm}$. Top trace represents voltage step and bottom trace current in response to it. The decay of the outward current is shown on a semi-logarithmic plot in the right of each panel. $\left[\mathrm{K}^{+}\right]_{\mathrm{a}}, 40 \mathrm{~mm}$. B: the time constant-voltage relation with $\left[\mathrm{K}^{+}\right]_{\mathrm{i}}$ of $75 \mathrm{mM}$ (filled circles) and $150 \mathrm{~mm}$ (filled triangles). The average of 5 experiments at each $\left[\mathrm{K}^{+}\right]_{\mathrm{i}}$ is plotted against the voltage step $(\Delta V)$ from the zero-current potential. The time constant of the inward and outward current decreased exponentially as the voltage step was increased. The time constant-voltage relation was superimposable in the inward direction, while the slope was less steep with $75 \mathrm{~mm}\left[\mathrm{~K}^{+}\right]_{\mathrm{i}}$ than with $150 \mathrm{~mm}\left[\mathrm{~K}^{+}\right]_{\mathrm{i}}$ in the outward direction. $\left[\mathrm{K}^{+}\right]_{0}, 40 \mathrm{~mm}$.

channel described here may be more or less influenced by the remaining $\mathrm{Mg}^{2+}$ and not completely "intrinsic." The activation kinetics of the cardiac inwardly rectifying $K$ channel has been studied mainly on the inward currents, in the cell-attached configuration of single-channel current recordings (KURACHI, 1985) and in the whole-cell clamp experiments (TourneUR et al., 1987).

Several findings support the idea that the outward current under investigation flows through the inwardly rectifying $K$ channel. 1) The amplitude of the instantaneous current was on the line extrapolated from the measurement of the inward current at different $\left[\mathrm{K}^{+}\right]_{\mathrm{o}}$ and $\left[\mathrm{K}^{+}\right]_{\mathrm{i}}$. 2) The peak outward current developed in parallel with the increase of the inward current during the preceding hyperpolarization (Fig. 2). 3) The current was suppressed by omitting $\mathrm{K}^{+}$from the external solution, by applying $\mathrm{Ba}^{2+}$ in the external solution, or by $\mathrm{TEA}^{+}$on either side of the membrane (not shown). These conditions are known to depress the 


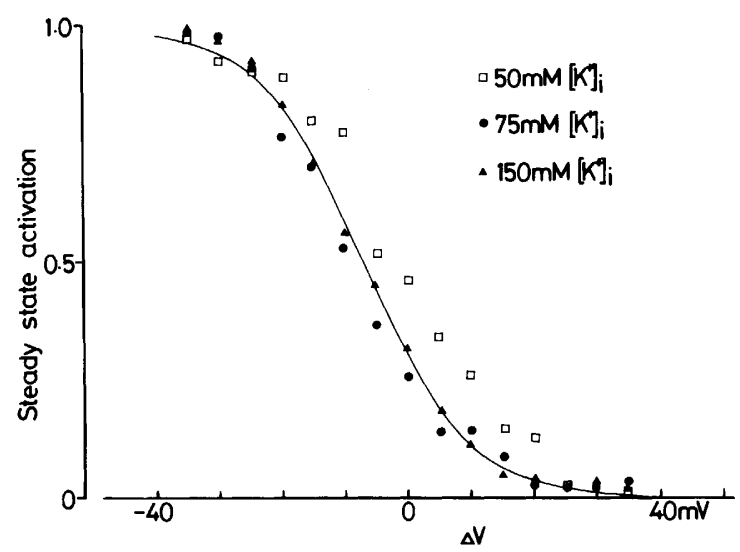

Fig. 9. The steady-state activation curves determined using $50 \mathrm{~mm}-\mathrm{K}^{+}$(open squares, $n=4$ ), $75 \mathrm{~mm}-\mathrm{K}^{+}$(filled circles, $n=5$ ), and $150 \mathrm{~mm}-\mathrm{K}^{+}$(triangles, $n=9$ ) internal solutions. The degree of activation was measured with the same method as in Fig. 6. The curve was fitted to the data with $150 \mathrm{~mm}\left[\mathrm{~K}^{+}\right]_{\mathrm{i}}$. Slope factor, $8.9 \mathrm{mV}$; half activation voltage, $E_{\mathrm{K}}-5.7 \mathrm{mV} .\left[\mathrm{K}^{+}\right]_{0}, 40 \mathrm{mM}$.

inwardly rectifying $\mathrm{K}$ current. 4) The outward current could be elicited by voltage steps from a relatively low potential and at a high frequency (Fig. 3), excluding the contribution of the transient outward current. 5) The time constants of decay during depolarization and those of activation during hyperpolarization were well explained by a common bell-shaped curve. 6) The single channel analysis disclosed an outward single-channel current through the inwardly rectifying $\mathrm{K}$ channel and the average current showed a time-dependent decrease similar to that obtained with the whole-cell current recording (MATSUDA et al., 1987).

The decay of the outward current was fitted with a single exponential at voltages below $E_{\mathrm{K}}=+30 \mathrm{mV}$. Above this voltage, it required two exponentials for fitting. The time constant of the fast component was less than $1 \mathrm{~ms}$. We ascribe this to incomplete removal of the capacitive current and limit the voltage range for analysis to $E_{\mathrm{K}}<+30 \mathrm{mV}$. The instantaneous current-voltage relations were linear in 15 out of 21 cells and the remaining cells showed inward rectification. In the present experiments, free $\mathrm{Mg}^{2+}$ concentration of the pipette solution calculated using the apparent dissociation constants of EGTA was $15 \mu \mathrm{M}$. The actual intracellular $\mathbf{M g}^{2+}$ concentration is predicted to be higher than this value considering the physiological intracellular free $\mathrm{Mg}^{2+}$ concentration ranging from 0.5 to $3.5 \mathrm{~mm}$ (Hess et al., 1982; Gupta et al., 1984; Blatter and MCGuigan, 1986) and limited efficiency of the internal perfusion. Recent single-channel current study has shown that the halfsaturation concentration of the $\mathrm{Mg}^{2+}$ block was $1.7 \mu \mathrm{M}$ at $E_{\mathrm{K}}+70 \mathrm{mV}$ (MATSUDA, 1988). Thus if we could have measured the instantaneous current-voltage curves at more positive potentials, most of them might have shown the inward rectification owing to the voltage-dependent $\mathrm{Mg}^{2+}$ block. We cannot tell at the present whether 
the effects of internal $\mathrm{Mg}^{2+}$ on the measurement of the steady-state activation curves and the time constants were small or not in the voltage range examined. In spite of the uncertainty about the influence of $\mathrm{Mg}^{2+}$, the present work gives the first quantitative analysis on the outward current through the inwardly rectifying $\mathrm{K}^{+}$ channels.

The time constant of the activation or deactivation of the channel decreased exponentially as the voltage step from $E_{\mathrm{K}}$ was increased and the time constantvoltage relation was bell-shaped with the peak at around $E_{\mathrm{K}}$. The decrease in the time constant with larger depolarization was reported in the egg cell membrane (HaGiwara et al., 1976) and the frog skeletal muscle (Hestrin, 1981). Other workers suggested that the time constant becomes larger at more positive potentials in the frog skeletal muscle (LEECH and STANFIELD, 1981).

The present results showed that the gating of the channel depends on the driving force rather than the membrane potential alone. This notion holds in the potential range above $E_{\mathrm{K}}$, and in contrast with previous reports, when $E_{\mathrm{K}}$ is altered with changing internal $\mathrm{K}^{+}$at a fixed external concentration. No outward current flows in the absence of external $\mathrm{K}^{+}$, suggesting that there is a binding site accessible to external $\mathrm{K}^{+}$but not to internal $\mathrm{K}^{+}$and that the occupation of this site by $\mathrm{K}^{+}$is essential for the channel to open. Our finding may indicate the presence of an additional binding site to which both external $\mathrm{K}^{+}$and internal $\mathrm{K}^{+}$have access to affect the gating kinetics.

We thank Professors H. Irisawa and A. Noma for helpful advice and discussion and Professor P. R. Stanfield for reading the manuscript. This work was supported by a Grant-inAid from the Ministry of Education, Science and Culture of Japan.

\section{REFERENCES}

BlatTer, L. A. and MCGuigan, J. A. S. (1986) Free intracellular magnesium concentration in ferret ventricular muscle measured with ion-selective micro-electrodes. $Q$. J. Exp. Physiol., 71: 467-473.

CARMeliet, E. and VereeCKe, J. (1979) Electrogenesis of action potential and automaticity. In: Handbook of Physiology, Sec. 2, The Cardiovascular System, Vol. 1, The Heart, ed. by Berne, R. M., Sperelakis, N., and Geiger, S. R., Am. Physiol. Soc., Bethesda, Maryland, pp. 269-334.

Fabiato, A. and Fabiato, F. (1979) Calculator programs for computing the composition of the solutions containing multiple metals and ligands used for experiments in skinned muscle cells. J. Physiol. (Paris), 75: 463-505.

Gupta, R. K., GuPta, P., and Moore, R. D. (1984) NMR studies of intracellular metal ions in intact cells and tissues. Annu. Rev. Biophys. Bioeng., 13: 221-246.

Hagiwara, S., Miyazaki, S., and Rosenthal, N. P. (1976) Potassium current and the effect of cesium on this current during anomalous rectification of the egg cell membrane of a starfish. J. Gen. Physiol., 67: 621-638.

Hagiwara, S. and Ohmori, H. (1982) Studies of calcium channels in rat clonal pituitary cells with patch electrode voltage clamp. J. Physiol. (Lond.), 331: 231-252. 
Hagiwara, S. and TAKAHASHI, K. (1974) The anomalous rectification and cation selectivity of the membrane of a starfish egg cell. J. Membr. Biol., 18: 61-80.

Hagiwara, S. and YoshiI, M. (1979) Effects of internal potassium and sodium on the anomalous rectification of the starfish egg as examined by internal perfusion. $J$. Physiol. (Lond.), 292: 251-265.

Hamill, O. P., Marty, A., Neher, E., Sakmann, B., and Sigworth, F. J. (1981) Improved patch-clamp techniques for high-resolution current recordings from cells and cell-free membrane patches. Pflügers Arch., 391: 85-100.

Hess, P., Metzger, P., and Weingart, R. (1982) Free magnesium in sheep, ferret and frog striated muscle at rest measured with ion-selective micro-electrodes. J. Physiol. (Lond.), 333: 173-188.

HeSTRIN, S. (1981) The interaction of potassium with the activation of anomalous rectification in frog muscle membrane. J. Physiol. (Lond.), 317: 497-508.

ISENBERG, G. and KLÖCKNER, U. (1982) Calcium tolerant ventricular myocytes prepared by preincubation in a "KB medium." Pflügers Arch., 395: 6-18.

KURACHI, Y. (1985) Voltage-dependent activation of the inward-rectifier potassium channel in the ventricular cell membrane of guinea-pig heart. J. Physiol. (Lond.), 366: 365-385.

Leech, C. A. and Stanfield, P. R. (1981) Inward rectification in frog skeletal muscle fibres and its dependence on membrane potential and external potassium. J. Physiol. (Lond.), 319: 295-309.

Matsuda, H. (1988) Open-state substructure of inwardly rectifying potassium channels revealed by magnesium block in guinea-pig heart cells. J. Physiol. (Lond.), 397: $237-258$.

Matsuda, H. and Noma, A. (1984) Isolation of calcium current and its sensitivity to monovalent cations in dialysed ventricular cells of guinea-pig. J. Physiol. (Lond.), 357: $553-573$.

Matsuda, H., Saigusa, A., and Irisawa, H. (1987) Ohmic conductance through the inwardly rectifying $\mathrm{K}$ channel and blocking by internal $\mathrm{Mg}^{2+}$. Nature, 325: 156-159.

NaKayama, T. and Irisawa, H. (1985) Transient outward current carried by potassium and sodium in quiescent atrioventricular node cells of rabbits. Circ. Res., 57: 65-73.

Ohara, M., Kameyama, M., Noma, A., and Irisawa, H. (1983) Giga-seal suction electrode and its application to single cardiac myocytes. J. Physiol. Soc. Jpn., 45: 629-639.

OHmori, H. (1984) Studies of ionic currents in the isolated vestibular hair cell of the chick. J. Physiol. (Lond.), 350: 561-581.

Soesima, M. and Noma, A. (1984) Mode of regulation of the ACh-sensitive K-channel by the muscarinic receptor in rabbit atrial cells. Pflügers Arch., 400: 424-431.

Tourneur, Y., Mitra, R., Morad, M., and Rougier, O. (1987) Activation properties of the inward-rectifying potassium channel on mammalian heart cells. J. Membr. Biol., 97: 127-135. 